\title{
Hybrid Technologies for Interdisciplinary Education
}

\section{Shahin Vassigh ${ }^{1}$, Winifred E Newman ${ }^{2 *}$, Ali Mostafavi ${ }^{1}$ and Amir Behzadan ${ }^{3}$}

${ }^{1}$ Florida International University, United States

${ }^{2}$ University of Arkansas, United States

${ }^{3}$ Missouri State University, United States

\begin{abstract}
Integrated applications using Augmented Reality (AR) and Building Information Modeling (BIM), enhanced by the capacity of handheld devices, are becoming prevalent in the building industry; however their use in learning environments has not been fully explored. Recent research shows that interaction with computer-based tools can enhance learning and collaboration skills. Augmented Reality-the ability to enhance real world observations with computer-generated information- is bringing new dimensions to learning. Combining AR with computer modeling applications and other simulation technologies promises to guide the next generation of computer-based learning environments. This paper describes a learning environment, Ecocon, designed by the integration of AR, BIM, visual simulations, and interactive lessons to support collaborative and interdisciplinary learning for the Architecture, Engineering and Construction (AEC) fields. Building on theoretical perspectives and advances in the understanding of learning processes, cognition, and development, we describe the pedagogical principles for the design of a prototype tool to enhance AEC interdisciplinary education. The main features of the tool include: 1) using real-world or field contexts for delivering context-aware information and lessons, 2) enriching AR visualization with "intelligence," so augmented information is responsive to a user's location, and 3) providing data visualization to support learning.
\end{abstract}

Keywords: Augmented reality; Building information modeling; Collaborative learning; Interdisciplinary education; Sustainable building design and construction

\section{Introduction}

Research by the National Institute of Building Sciences and others indicates that the most resource efficient, best performing, and environmentally sustainable buildings are designed using Integrated Design. Integrated Design is a mode of interdisciplinary collaboration where engineers, architects, and construction professionals work together at the conception of a project to create synergy among various building systems in order to improve the overall building performance.

Promoting the practice of Integrated Design is recognized by the American Institute of Architects (AIA) as one of the central challenges facing the profession and an important ways to improve building performance, cost, environmental impact and innovation in the industry. The AIA 2030 Commitment challenged the profession to achieve the goal of designing carbon-neutral or no greenhouse gas emitting energy buildings in the U.S. identifying the practice of Integrated Design as the primary vehicle to attain this goal [1] In addition, innovation, developing new knowledge, and building effective decision making capacity to address complex problems of building industry demands collective intelligence that can only emerge from collaboration among experts with diverse disciplinary backgrounds. Responding to this challenge entails a holistic view and an understanding of a host of issues that go beyond the borders of existing institutional and educational entities. Successful collaboration requires professionals who have the skills to engage in effective interdisciplinary work environments. However, facilitating integrated practice is not a trivial challenge. This paper examines some of the current challenges and the necessity of interdisciplinary education and collaboration in building sciences, with a particular focus on Architecture, Engineering and Construction (AEC) students. By presenting a comprehensive literature review on collaborative and computer supported learning theories; the paper makes an argument for the use of advanced digital technology, particularly Augmented Reality for facilitating interdisciplinary education and collaboration. The paper describes a small-scale experiment for testing collaborative learning using $\mathrm{AR}$ technology and continues with a detailed explanation of a prototypelearning environment using integrated $\mathrm{AR}$ and BIM technologies.
Both environments are designed to enhance AEC interdisciplinary education in the area of sustainable design and construction.

\section{Educational Challenges}

Successful interdisciplinary collaboration requires competencies that transcend fluency of the core STEM subjects. It demands learning skills, an ability to understand and acknowledge other disciplines' perspectives and the ability to give and receive feedback from peers. In addition, the capacity for critical thinking and leadership as described by a one's ability to analyze, synthesize, and communicate information across disciplinary boundaries, is critical to interdisciplinary collaboration. However, there are challenges to sufficiently developing these skills in a typical AEC undergraduate education. The following paragraphs provide a brief overview of some of these challenges.

\section{Knowledge silos}

Many AEC students go through undergraduate education without any opportunity to engage with other disciplines. Disciplinary silos pose significant impediments in attaining a holistic understanding of the broader issues as the pillar of innovation and effective problem solving. Innovation is a novel insight stemming from the unique and creative integration of diverse ideas. Without a concerted effort to utilize novel research and pedagogical approaches and exposing students to activities involving people, ideas, and methods; disciplinary boundaries will continue to stand in the way of opportunities for innovative thinking and discovery that could lead to transformational solutions of critical issues.

*Corresponding author: Winifred E. Newman, University of Arkansas, Fayetteville AR 72701, United States, Tel: +1 479-575-2000; E-mail: wenewman@uark.edu

Received November 16, 2015; Accepted December 01, 2015; Published December 11, 2015

Citation: Vassigh S, Newman WE, Mostafavi A, Behzadan A (2015) Hybrid Technologies for Interdisciplinary Education. J Civil Environ Eng 5: 201. doi:10.4172/2165-784X.1000201

Copyright: $\odot 2015$ Vassigh S, et al. This is an open-access article distributed under the terms of the Creative Commons Attribution License, which permits unrestricted use, distribution, and reproduction in any medium, provided the original author and source are credited. 


\section{Critical thinking skills}

Critical thinking is one of the most important skills for future generations of college graduates, particularly for interdisciplinary collaboration. Developing critical thinking skills is the foundation for adaptive flexibility. This is defined by the ability to exercise sound reasoning in understanding and making complex choices, understanding interconnections among systems, and the ability to frame, analyze, and solve problems. Students need to know how to use knowledge and skills when applying them to new situations, analyzing information, comprehending new ideas, communicating, collaborating, solving problems, and making decisions [2].

\section{Interpersonal and self-directional skill}

According to the Council of Graduate Schools Report in 2012, many graduates from four-year colleges do not possess interpersonal, collaborative, and leadership skills and many leave the academy without a chance to acquire these skills. Stakeholders from the United States and other countries are asking higher education for a greater emphasis on knowledge of human cultures, intellectual and practical skills, and accepting social and personal responsibility [2]. Though largescale reform of STEM education is the subject of a complex, ongoing national debate; researching learning environments that support collaborative skills for interdisciplinary interaction is a critical step in addressing these challenges. Immersive technologies, simulation, data visualization, and easy-to-access geo-spatial datasets are creating new opportunities for educational interventions. Within this context, AR promises to enhance face-to-face communication by providing spatial cues to support group interaction.

\section{Collaborative Problem-Solving}

Computer-supported collaborative learning (CSCL) is an interdisciplinary paradigm concerned with learning processes mediated by computers [3]. Although the work of the CSCL community does not converge into a single theory or method, it builds on dialogic learning and human cognition theories. The socio-cultural model of learning focuses on how social interaction and cognitive development are tightly interconnected [4]. Vygotsky argues that the basic mechanism of cognitive growth is communicative in nature specifically that individual cognitive processes derive from inter-personal interactions. This places the study of interpersonal interactions, such as dialogues, at the center of learning research. A second aspect of Vygotsky's theory is the meditating role of artifacts in learning activity. Vygotsky argued that humans are unique in that they are born into environments shaped by the activities of previous generations and learning is enculturation into these existing structures. The human capacity to make and use artifacts is therefore a key component in our ability to learn as we enrich and extend knowledge through an individual's appropriation and mastery of the cultural inheritance [5]. CSCL research is strongly inspired by socio-cultural theory as researchers concur that communication and interaction mediated by artifacts is the central object of research [6]. Piaget and Papert's work on the incremental view of knowledge construction also influences CSCL research. Papert's theory of constructionism focuses on processes that help learners to connect new knowledge to what they already know. Papert, like Vygotsky, also stresses the role of physical objects in knowledge construction and refers to the term "objects to think with," holding the view that physical or digital objects help in construction and examination of the relationship between the new and old knowledge [7]. In the past decade, the work of the CSCL community influenced the study and design of computer-mediated learning significantly. By adopting different perspectives, including 'traditional' cognitive perspectives, several studies show that appropriately designed CSCL environments significantly improve learning outcomes. Although many of these studies focus on the impact of forms of communication mediated by digital technology, the CSCL approach with its emphasis on interaction and artifact use is suitable to study the role of augmented physical objects on collaboration. The studies on mixed reality environments show their effectiveness in single user applications, but their role in supporting collaborative learning has not been explored adequately.

\section{Augmented Reality Technologies}

AR interfaces blend the physical and virtual worlds such that real objects seem to interact with $3 \mathrm{D}$ digital content and improve users' shared understanding [8]. Research shows that new developments in $\mathrm{AR}$, coupled with improved user interface technology offer numerous opportunities in support of teaching and learning environments [8-10]. Summarizes recent findings on potential benefits of AR in education and asserts that AR: 1) engages, stimulates, and motivates students to explore lessons and concepts from different angles [11].2) Enhances learning where students could not feasibly gain real-world first-hand experience. 3) Promotes collaboration between students and teachers, 4) fosters student creativity and imagination [8]. 5) Aids students to control their learning at their own pace and on their own path [12] and 6) create an authentic learning environment suitable to various learning styles [13]. A second important technology available in the AEC professional is BIM or Building Information Modeling. Concurrent with increased cyber capacity, BIM transformed the AEC sector by providing 3D digital representation of buildings that facilitate convenient and highly efficient multi-professional collaboration. BIM models are used for design, development, engineering, highquality construction, document production, construction planning, performance predictions, and cost estimates. However, many agree that the core strength of BIM is $3 \mathrm{D}$ visualization. The enhanced visualization makes it easier to demonstrate design intent of the professional engineers and architects, enables intuitive understanding, and facilitates timely communication [14]. BIM models are the virtual equivalence of the actual building and can contain engineering and design data including structural, mechanical, electrical, and material metrics and quantities, as well as other information. In recent years, new developments in AR applications provide a unique opportunity for integrating AR interfaces with BIM models, moving academic research into new practical applications used in industry [15]. The integrated applications of AR and BIM models enhanced by the capacity of handheld devices are beginning to be used in the construction industry for planning virtual site construction, walk-though functions to facilitate design/constructability, onsite review of the design, and cost saving and safety measures. However, the use of integrated AR and BIM technologies for creating educational environments is at its infancy. In particular, the use of AR in integration with BIM and visualization technologies to facilitate collaboration has not been sufficiently explored.

\section{Testing collaborative learning}

Using a small seed grant From Florida International University a small group of faculty conducted an experiment to examine how collaboration could work among architects and engineers. The goal of the experiment was to study the differences between individual and collaborative learning strategies among AEC students. The experiment asked if student collaboration would result in the design of more efficient and sustainable buildings. The experiment was structured as follows: two groups of students were given the task to design and assemble of a small-scale building from a given kit of parts. The main 
goal was to design an energy-efficient building with minimal impact on the environment. During the process students were given access to disciplinary content, lessons and information about the climate and the locale of the building, as well as existing strategies that could be incorporated into the design. In addition, textual and graphic handouts accompanied each element with respect to its particular metrics and attributes. Group 1 Students acted independently assuming their respective roles as Architect, Mechanical Engineer, and Construction Manager. The students consulted each other as necessary. Group 2 students collaborated from the beginning of the project and stayed together to complete the building assembly. The experiment was closely monitored and student interactions were recorded. The assembled building for each group was collected and modeled in a digital format with the inclusion of individual elements' metrics. Both buildings were analyzed with Energy Plus software for cost, carbon footprint, and energy consumption. The resulting data showed that the Group 2 building, assembled through collaborative effort, performed better in all categories of energy consumption, embodied energy, embodied water, and life-cycle cost, but the initial cost of construction was higher. Later analysis showed that the initial cost increase was offset after five years due to the resulting energy savings. To understand the process, we reviewed video recordings of student interactions and observed that students were initially hesitant about voicing their opinion in decisions not directly related to their disciplines. However, as they spent time together negotiating and discussing the decision-making process, their natural disciplinary constraints and conflict of interests resulted in a richer and more nuanced discussion of fundamental concepts that we believe contributed to the success of the group project. In the exit interview, students working in the more effective Group 2 identified two challenging aspects of the experimental setup. First, was the difficulty of negotiating across disciplinary boundaries without any guidance or boundaries framing the discussions, and the second was the amount of time it took and stopping the discussions to look for information that they could not access effectively through the provided package. In conclusion, the experiment of observing the group negotiations, learning processes, and sources of frustration, became a basis for exploring new ways to facilitate interdisciplinary collaborations. Based on their research faculty conducting the experiment believe that integrating AR and BIM technology in a user friendly application can facilitate this kind of collaboration.

\section{Ecocon learning experience}

To explore learning possibilities associated with the integration of immersive technologies with visual simulations, the same faculty team is developing a collaborative learning environment called "Ecoconstruction" or "Ecocon" to support sustainable building design and construction for AEC students. Ecocon is designed to create a realistic and immersive experience for learning how buildings are assembled. It allows students to field investigate actual buildings while providing location-sensitive information and supplemental on-demand lessons. Moreover, it aids students to gather critical information for solving interdisciplinary group problems. The following section describes Ecocon components and use. The User Interface includes a main and a secondary window. The main window is where the BIM model of the building is downloaded. These are models of selected buildings on the main campus of the Florida International University (FIU). The interface uses GPS allowing the model to work with the user location and adjust views accordingly. The secondary window- located on the right side of the interface-is reserved for Learning Modules that deliver pedagogical concepts and relevant lessons. Learning Modules are accessed through the navigation bar at the bottom of the interface and they include limited lessons on: 1) Site and Orientation, 2) Construction Methods, Cost and Schedule, 3) Foundation Systems, 4) Structural Systems, 5) Climate Control Systems, 6) Building Envelope, and 7) Natural Lighting. Learning Modules can be accessed at two distinct levels for Novice and Expert users. Each of the seven icons on the navigation menu bar will present both these options. The Novice level provides an introduction to concepts communicated across the three participating disciplines for effective collaboration, and is accessible to all team members. The Expert level provides more in-depth lessons and analytical methods and processes designed for in-discipline learning. Ecocon design is based on the idea that learning is fundamentally a process by which learners build a deep understanding of the subject by cycling through experiencing, reflecting, thinking, and acting in response to a contextual setting. The learning experience with the Ecocon environment is designed to facilitate this process by: 1) creating a realistic context for interaction, 2) supplementing student observations with critical information, 3) providing opportunities for reflection with peers, and 4) responding to scenarios by acting out as an expert. Ecocon will be implemented in three interdisciplinary courses at FIU from Mechanical Engineering, Construction/Civil Engineering, and Architecture respectively taught by the Co-PIs of the proposed project. Courses are taught by each department utilizing the learning modules and following a closely coordinated curriculum. The semester work is divided into four-week units: 1) Siting and Foundations, 2) Building Systems, 3) Construction Methods, and 4) Post Occupancy Evaluation. Upon completion of each unit, students form interdisciplinary teams and engage in a one-day collaborative assignment. Teams of three students comprised of one from each discipline visit a building on the FIU's main campus and use the Ecocon application to gather pertinent information in relation to the completed unit. Information is collected in both qualitative and quantitative formats, for building analysis and sustainability performance. Information can be obtained using the screen capture functionality/camera of a handheld device. Upon the completion of the site visit, the teams reconvene, share information, discuss, analyze the particular systems performance (both qualitative and quantitative), and submit a Technical Report. The Report is comprised of two sections to be addressed by each team: 1) rate the building performance in its current conditions, and 2) respond to a Scenario, which changes the context and existing conditions of the building (Table 1) (Figures 1 and 2).

\section{The following is a typical project Scenario describing how we envision students interacts with Ecocon}

It is the 12th week of the semester and the participating classes finished the "Climate Control Systems" unit. Students receive a twoweek assignment designed to help them apply their understanding of climate control systems and envelope systems to a real building context on the Campus. Team "A" divides up the site visit into various tasks for each member. Once they arrive at the building site, each member starts Ecocon on a mobile device. A team member points her device's camera lens toward an exterior wall. Ecocon allows her to visualize the entire wall assembly using layers of information: structure, wall composition, façade elements, and the assembly system. She focuses on the wall elements by turning off the extraneous layers to view its construction. The concrete wall assembly she is looking at is composed of reinforced concrete, gypsum board, insulation, metal furring, window casing, form tie, aluminum window frame, and double glazed window system. She is also able to see the list of these materials with their thermal resistance (R-value) and embodied energy. She keeps taking pictures with her device documenting critical information from various components and their properties. Another teammate enters the building with his 
Citation: Vassigh S, Newman WE, Mostafavi A, Behzadan A (2015) Hybrid Technologies for Interdisciplinary Education. J Civil Environ Eng 5: 201. doi:10.4172/2165-784X.1000201

Page 4 of 5

\begin{tabular}{|l|l|}
\hline Course Work & Assignment Activity Focus FIU Campus \\
\hline Unit 1: Sting and Foundations & $\begin{array}{l}\text { Soil type and conditions. Climatic Conditio } \\
\text { Prep. Foundation Type, Site Geometry, } \\
\text { Building Orientation \& Geometry, Conditio } \\
\text { for Natural Lighting }\end{array}$ \\
\hline Unit 2:Building Structural and & $\begin{array}{l}\text { Structural Materials, seizing, framing type, } \\
\text { connections, structural/nonstructural building } \\
\text { envelope/walls. }\end{array}$ \\
\hline Unit 3:climate control systems and \\
carbon foot print & $\begin{array}{l}\text { Mechanical/ Active (HAVC), systems pass } \\
\text { heating \& cooling technology, Carbon } \\
\text { natural design. Envelope materials thermal } \\
\text { properties, embodied energy \& climate } \\
\text { responsive technology }\end{array}$ \\
\hline Unit 4: Construction Methods & $\begin{array}{l}\text { Construction Methods, Equipments and } \\
\text { materials, safety, sustainable construction } \\
\text { cost estimation and scheduling }\end{array}$ \\
\hline & \\
\hline
\end{tabular}

Figure 1: Ecocon learning.

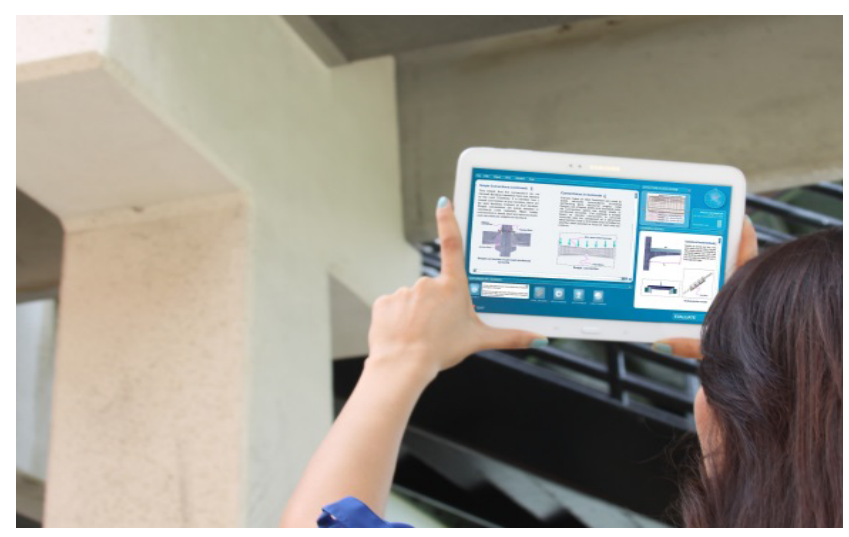

Figure 2: Ecocon learning-User interface.

handheld device. He gets visual access to the mechanical, electrical, and plumbing system from inside the building. He zooms on the mechanical system, finds the mechanical unit, and investigates its capacity, type, and function. Using the Climate Control Systems/ Active Cooling Module, right at that moment, he is able to identify that cooling is provided by Water Chillers. He starts an animation to see how the various components of the water chiller including compressor,

\section{scenario/ New Conditions}

Move the building from the existing and hot and humid climate located on a flat sandy soil to a cold climatic conditions located on a slopped clay site (a particular site will be provided)

Move the building from the existing hurricane prone area to a seismic zone (a particular site will be provided)

Reduce the building carbon foot print by a certain percentage for improving its impact on the environment (appropriate percentage will be provided)

Improve the performance of project in terms of cost, schedule, safety and construction waste (appropriate percentage will be provided)

\section{Technical Report Recommendations}

New foundation type and configuration, building orientation and form for best thermal response, addressing the new conditions for natural lighting.

New or added structural systems for seismic performance, changing or reinforcing building envelope for improving seismic performance

New or improved HVAC and passive for enhanced energy performance, improved or new building materials to increase thermal resistance, reduce embodied energy using alternative materials.

Modified construction plan and alternative methods and materials to reduce cost schedule and waste on the project and improve safety aspects.

ject Activities.

evaporator, and condenser work to provide cool air supply for the building. He walks around and investigates other systems by turning on/off other layers of the building's BIM model. The third teammate uses her device to view different components of the building and learn about the required construction activities. She focuses on the HVAC system and sees the list of construction activities (e.g., installation of air ducts and insulation) involved. She selects each construction activity and identifies the major equipment utilized and its corresponding level of emissions and wastes. She also obtains information related to the life cycle impacts of the materials (e.g., ducts and pipes) and equipment (e.g., radiator and heat pumps). By the end of her visit, she can identify what construction activities related to the Climate Control System unit have the greatest level of emission and waste. Upon completion of the site visit, the team reconvenes to reflect on their observations, discuss findings, compare notes, and address the Scenario. The Scenario for this unit is charging the team to reduce the carbon footprint of the building by $15 \%$ (see Table 1, unit 3 ). In this case, the teamwork was divided into tasks regardless of their disciplinary training. Therefore, in order to understand how the building works, and how to begin their analysis they share information, discuss what they have seen, and strategize their next move. In the following steps that involve analysis and redesign the disciplinary expertise of the team members becomes critical. The Architect has a better understanding of the façade material properties and can easily understand the Expert Level of the Learning Module. This will help him access information on how to calculate the carbon footprint and the possible strategies to respond to the given Scenario. The Mechanical Engineer is better prepared to calculate chiller capacity, evaluate efficacy, and end energy efficiency. The Construction/Civil Engineer better understands construction methods and materials. This will help her evaluate the waste and environmental impacts related to different construction methods and materials as well as identify the best alternatives. The team moves between expert input and general discussion, responds to various concerns and viewpoints, and finally provides its assessment and recommendations in the Technical Report. The team may have to meet 2-3 times in order to complete the Technical Report and submit it for evaluation.

\section{Research Questions}

Upon completing of the prototype, testing and assessment of the project the team will address the foundational research question of "how does integration of immersive technology with BIM models 
and interactive learning simulations, impact conceptual development and interdisciplinary learning?" the project research plan provides a roadmap to address this question by examining student interaction with Ecocon and addressing the following detailed, measurable, and focused research questions:

1. How does engaging with Ecocon impact students' problemsolving skills and collaborative learning interactions?

2. How does interaction with the project change students' understanding of building science principles in their respective disciplines?

3. Do we of Ecocon enhance the ability of students to successfully transfer the principles they have learned to new situations?

4. What is the impact of the use and the project approach on student motivation for further collaborative learning?

To investigate these questions, we use Design-based Research, a systematic and flexible methodology for carrying out studies of educational interventions. Based on iterative testing the approach is pragmatic, integrative, and contextual. Design-based research involves the analysis of the use and performance of the artifact being developed to understand, explain, and improve its attributes for learning [16]. This method uses progressive refinement by testing, analyzing, and refining the design from very early stages of development [17]. As Collins [17] states, the approach is particularly important because unlike traditional laboratory experiments, pedagogical experiments are set in real-world learning environments where there are many variables that cannot be controlled. Instead, design researchers try to optimize as much of the design as possible and to observe carefully how the different elements are working. We believe this method allows observations and analysis of student engagement with the project and collaboration during project testing, and guides decisions regarding project developments. The research plan has three objectives: 1) formative assessments and iterative improvement of the project based on collected data during project implementation, 2) developing effective methods for analysis of the data to determine if student learning outcomes have changed, and if the change is based on our intervention, and 3) providing a summative evidence of research outcomes. We will employ a range of both quantitative and qualitative data collection methods and statistical analysis.

\section{Concluding Remarks}

The challenge of preparing students to participate in a collaborative world presents new opportunities to enhance learning. Recent educational research shows that knowledge developed through dialogue and active interaction with peers and the environment is robust and long lasting. As a result, facilitating collaboration with effective learning environments not only enhances students' ability for teamwork and collaborative skills it also potentially improves performance and learning. There is little known about how people learn and collaborate using the integration of AR, digital modeling and other simulation technologies can contributes to advancing the design of learning environments using new and emerging media. The described tools' focus on facilitating collaboration among AEC disciplines has far reaching impacts. Given the growth of the extents of the built environment, climate change, and increased energy and material consumption in the building and construction industry, increasing the aptitude of building scientists, engineers, and architects to design more efficient and sustainable buildings is critical. A broader education of engineers and architects emphasizing collaboration and leadership and communication skills leads to increased innovation, enhancing sustainability, and reduced cost of training once they enter the work force.

\section{References}

1. American Institute of Architects (AIA) (2014) Architecture 2030 Will Change the Way You Look at Buildings.N.p. Web.

2. Partnership for 21 st Century Skills, Learning for the $21^{\text {st }}$ Century.

3. Stahl G, Koschmann T, Suthers D (2006) Computer-supported collaborative learning: An historical perspective. Cambridge handbook of the learning sciences.

4. Doise W, Mugny W (1984) The Social Development of the Intellect. Oxford: Pergamon Press.

5. Wells G (1999) Dialogic Inquiry in Education. Building on the Legacy of Vygotsky 51-85.

6. Sawyer RK (2006) The Cambridge Handbook of The Learning Sciences. New York, NY: Cambridge University Press.

7. Kafai YB (2006) Constructionism. The Cambridge Handbook of The Learning Sciences. New York, NY, Cambridge University Press. pp. 35-46.

8. Billinghurst $\mathrm{M}$, Kato H (2002) Collaborative Augmented Reality. Communications of the ACM. 45.7: 64-70.

9. Yuen S, Yaoyuneyong G, Johnson E (2011) Augmented Reality: An overview and five directions for AR in education. J Educational Technol Development and Exchange 4: 119-40.

10. Klopfer E, Squire K (2008) Environmental Detectives - the development of an augmented reality platform for environmental simulations. Educational Techno Res Development 56: 203-28.

11. Kerawalla L, Rosemary L, Simon S, Adrian W (2006) Making it real. Exploring the potential of augmented reality for teaching primary school science.

12. Hamilton K, Olenewa J (2012) Augmented reality in education. Autho STREAM. N.p., n.d. Web.

13. Classroom Learning with AR. Np Web.

14. Wang F, MJ Hannafin (2005) Design-based research and technology-enhanced learning environments. Educational Technol Res development 53: 5-23.

15. Siami M (2013) 4D BIM for Construction.

16. Wang X, Truijens M, Hou L, Wang Y, Zhou Y (2014) Integrating Augmented Reality with Building Information Modeling: Onsite Construction Process Controlling for Liquefied Natural Gas Industry. Automation in Construction. Elsevier Sci 40: 96-105.

17. Collins A, Josep D, Bielaczyc K (2004) Design research: theoretical and methodological issues. J Learning Sci 13: 15-42. 